Article

\title{
"How Do We Put Him in the System?": Client Construction at a Sport-Based Migrant Settlement Service in Melbourne, Australia
}

\author{
Jora Broerse \\ Institute for Health and Sport, Victoria University, Melbourne, VIC 8001, Australia; E-Mail: jozefien.broerse@live.vu.edu.au
}

Submitted: 30 October 2018 | Accepted: 17 January 2019 | Published: 28 February 2018

\begin{abstract}
The empirical focus of this article is a sport-based settlement service targeting newly arrived migrants in Melbourne, Australia. This five-month study examines staff members' everyday work routines with a focus on their participation in meetings and the production of documents. Embedded in the Australian immigration policy context, this article shows how staff members aim to empower clients while simultaneously falling back into stigmatising refugee/client identification through administrative practices. The results indicate that staffs' everyday client constructions reinforce the othering and categorisation of ethnic minorities and support a reductionist deficit model of presenting clients. This may limit the opportunities for migrants to identify with and participate in wider Australian society and thus has the opposite effect of what governments and the sector aim to accomplish.
\end{abstract}

\section{Keywords}

Australia; client construction; migrant settlement; policy design; sport-for-development

\section{Issue}

This article is part of the issue "'Producing People' in Documents and Meetings in Human Service Organizations", edited by Malin Åkerström (Lund University, Sweden) and Katarina Jacobsson (Lund University, Sweden).

(C) 2019 by the author; licensee Cogitatio (Lisbon, Portugal). This article is licensed under a Creative Commons Attribution 4.0 International License (CC BY).

\section{Introduction}

In recent decades, sports have been given attention in social public policy as a setting where refugees and asylum seekers experience a sense of social inclusion and belonging (Coalter, 2007; Olliff, 2008; Spaaij \& Broerse, 2018). Policymakers, advocacy groups, and communitybased organisations promote and invest in sport as a tool for the settlement of young people with refugee backgrounds (Jeanes, O'Connor, \& Alfrey, 2015; Refugee Council Australia, 2010). In Australia, the management of cultural diversity and migrant integration is on the agenda from national ministries to local municipalities and from schools to sports clubs which points to the importance of understanding how migrant integration is 'done' by grassroots (public) institutions.

In an attempt to better understand these processes on an institutional level, this article follows Schneider and Ingram's (1993) approach of researching policy design. The policy design process is often a contested and creative process that involves selecting the target group population and other elements. Designs are embedded in social constructions, images, and symbols that send messages not only to the target population, but also to the broader public of who needs what and how benefits and burdens are distributed (Schneider \& Ingram, 1993). This study focuses on a sport-based settlement service in Melbourne, Australia, and describes how staff members socially construct their clients with a focus on staff meetings and the production of documents. These bureaucratic practices can have a profound impact on client categories; the way sports programs are designed and implemented carry, implicitly or explicitly, notions of problem and solution definitions and (negative) constructions of client populations. These practices are situated in a dialectic context with top-down expectations formulated in discourses, laws and rules, and space for staff to respond bottom-up to manoeuvre regarding the concrete management of situations and individuals (Fassin, 2015). This article describes the constant struggle staff find 
themselves in: breaking free from a staff-client power relation and empowering clients while being pulled back into a stigmatising refugee or client identity.

The service offers various sports and non-sports programs for newly arrived migrants and aims to contribute to migrants' linguistic and cultural literacy. The service provides various sports programs ranging from one-day to six-week periods. Non-sports programs include healthy living programs, employment courses, and empowerment programs. The client population consists of so-called migrants of culturally and linguistically diverse backgrounds and are referred to by staff as "clients", "(sport/program) participants" or "students". The terms are used interchangeably; I will refer to clients in this article for consistency. Clients have navigated divergent migration pathways; some left their home countries in a state of war and entered Australia on a refugee or other humanitarian visa whereas others followed family members or seek better education or employment opportunities. The service runs approximately ten different programs, some of which are offered multiple times per year and each attracts about thirty clients. The service mainly depends on a three-year grant by the Australian Department of Social Services in collaboration with English language schools to reach its clients. After three years, the provider will compete with other settlement services in Melbourne to secure another funding cycle. Along with the funding cycle, the department has a set of requirements that need to be addressed. Three examples include: clients must not have spent more than five years in Australia; the programs should reach a minimum number of participants; and statistics of participants (e.g., demographics, length of stay in Australia, visa category) are to be collected and reported.

Based on a five-month qualitative study, I demonstrate that staff members' practices and client constructions follow a reductionist deficit mode of reasoning. A deficit mode of reasoning portrays people as being needy victims, under-educated and culturally "different" (Coakley, 2011). A focus on clients' ethnic background and visa category reinforces an us/them binary between 'established' and 'newcomers'. I argue that this may limit the discursive opportunities for identification and participation of migrants in wider society, and thus may have the opposite effect from what governments and the sport-for-development sector aim to accomplish (cf. Robertson, 2018; Roggeband \& Verloo, 2007).

This article is structured as follows: I first discuss the immigration and integration debates in Australia, followed by the perceived role of sport-for-development in integrating and supporting newly arrived migrants. The next section describes the methodology of the study. I then discuss the theoretical framework and finally present the ethnographic data.

\section{Managing Difference: The Australian Context}

The political arena of most Western nation-states is currently concerned with increasing migratory pressures and have created complex systems of civic stratification (Kofman, 2005). Societies that have been receiving high numbers of migrants and asylum seekers have increasingly developed complex migratory regimes resulting in many migrant and visa categories. This section briefly discusses how migrant integration and ethnic difference is managed in Australia.

An important aspect in understanding the migration rhetoric is looking at multiculturalism debates. Australia embraced multiculturalism in the 1970 s as a project of national identity renewal. Many state and local governments promote the virtues of multiculturalism to give recognition to the growing importance of religious and ethnic diversity (Bouma, 2006). In this narrative, social inclusion of newly arrived migrants can be achieved through multiculturalist policies that harness Australia as a country of many ethnicities and cultures (Moran, 2011). Young (2000) describes social inclusion, while highlighting its assimilationist character, as making social and economic deviants fit into dominant norms and institutions and providing them with equal education and welfare opportunities.

The demographic diversity has also caused anxiety about social cohesion and the maintenance of Anglocultural hegemony. Post-second world war, the notorious White Australia policy weakened but was soon followed by new expressions of opposition to diversity and multiculturalism including the Blainey Debate in the 1980s (Markus, 2014) and the rise and fall of the rightwing One Nation party in the 1990s and its resurgence in the 2016 federal election. Migrant settlement and integration in this context are framed as policy issues concerned with maintaining 'Anglo culture' and assimilating newcomers into the existing social, cultural, and political system. Australia's current humanitarian program focuses on temporary protection, place-based resettlement, and refugees' economic contribution (Boese, van Kooy, \& Bowman, 2018). Immigration policies encourage refugee settlement in regional and rural areas with skills shortages, instead of congested urban areas such as Melbourne and Sydney.

The migration discussion is further characterised by the disproportionate public anxiety asylum seekers provoke that other migrant categories (such as students and skilled workers) do not raise. This anxiety is strengthened through linking this migrant group to perceived illegal status with religious and racial categorisation in the context of Islamophobia (Klocker \& Dunn, 2003). Australian diversity politics and policy are further underpinned by an essentialist groupism approach, categorising minority groups on the basis of country of birth or ethnic, linguistic, or religious background (Anthias, 2012). For example, the Australian Census measures self-reported ethnic, religious, and language background. The social service and social policy sectors often employ the categories "non-English speaking" and "culturally and linguistically diverse" to describe target populations and to refer to non-Indigenous ethnic groups other than the 
English-speaking Anglo-Saxon majority. A growing body of research, however, shows ethnic and cultural identities are becoming increasingly complex and hybrid due to the diversification of migration patterns, inter-marriage, and generational changes (Harris, 2009).

In Australia, visa categories are as complex and varied as people's migration trajectories. Similar to the "nonEnglish speaking" and "culturally and linguistically diverse" categories, Australian sociologists have been slow in critically analysing taken-for-granted migrant classifications, even though the migration and super-diversity complexity is rapidly emerging in Australia (Robertson, 2018). A critical analysis is important because the manner in which migrant categories are constructed "can work to diminish their capacity and divide and exclude" (Robertson, 2018, p. 4).

Sport-for-development initiatives operate in and are part of this system. They are a product of a time in which high pressure is placed on creating a national identity, maintaining Anglo-cultural hegemony and preparing newcomers to be functional citizens. In the next section, I will discuss the role of sport-for-development in managing difference and as an integration policy tool.

\section{Migrant Settlement through Sport-for-Development Initiatives}

Sport is often perceived as a suitable policy tool to battle social problems, such as managing cultural differences in the context of immigration (Coalter, 2007). Olliff (2008) notes that since the 2000s, numerous government sport-for-development initiatives have been established in Australia, as part of a global movement, focussing on sports and recreational programs. The relation between sport and social outcomes has been thoroughly scrutinised and is often found to be uncritically determined (see, e.g., Houlihan, Bloyce, \& Smith, 2009). However, when implemented under the right conditions, sport can achieve a range of welfare objectives concerned with the settlement of newcomers (Coalter, 2010; McDonald, Spaaij, \& Dukic, 2018).

The use of sport as a means for integration is strengthened and justified by the way sport is continuously described as part of the Australian national identity. Rowe (2017) refers to Australian Citizenship: Our Common Bond, which contains the required study content for the Australian citizenship test, to describe the institutional value sport has in Australian culture. The section on sport and recreation, for example, states that "many Australians love sport and many have achieved impressive results at an international level", and that "throughout history, sport has both characterised the Australian people and united us" (Commonwealth of Australia, 2014, p. 43). Rowe (2017, p. 1473) concludes that such a "state-initiated endorsement of sport means that there is a clear association between sport and 'Australianness' and a general expectation that embracing sport is part of becoming an Australian".
Sport is not only considered to be essential to the Australian identity, but also as a site for "active citizenship" (Spaaij, 2013) and as a "breeding ground" for future national representatives (McDonald, 2016). Both Spaaij (2013) and McDonald (2016) demonstrate how these sport sites are products of neoliberal governing characterised by limited state involvement, individualism, and the promotion of market solutions (Walsh, 2014). Coakley (2011) further critically describes how neoliberalism shapes the sport-for-development industry. Social problems are individualised within sport-fordevelopment programs focusing on "personal growth that is based on planned skill development combined with pep talks emphasising internal reflection, endless possibilities, [and] 'being all they can be'"' (Coakley, 2011, p. 78). Moreover, sport-for-development programs are often organised around a deficit reduction model with people being portrayed as needy victims of drought, civil war, and general social disorganisation and are presented as under- or non-educated and culturally 'different'. Sport-for-development initiatives are currently a product of, and reinforce, a neoliberal agenda in which ethnic minorities are othered from the mainstream and need to be governed and be made to "reach the inside" of society (Ekholm \& Dahlstedt, 2017; McDonald, Rodriguez, \& George, 2018).

\section{Theory}

Whereas the previous section described the potentials of and critiques on sport-for-development initiatives, the question remains regarding how the programs relate to policy design, how they are implemented and thereby really 'produced' (cf. Fassin, 2015). This article draws on two bodies of literature: the first one, Schneider and Ingram (1997), provides lenses to understand the discursive power of policies and client construction; the second describes the role of local institutions in the formation and implementation of policies.

\subsection{Policy Design and Client Construction}

Policies are often formed to respond to perceived social problems (Stone, 2011). In this process, troubles are formulated and turned into problems to make them manageable and while these problems have objective qualities, they are also subjectively defined (Gubrium, Andreassen, \& Solvang, 2016). Schneider and Ingram have contributed extensively, both collaboratively and independently, to a critical understanding of policy design over nearly three decades. The theory posits "that the social construction of a social group interacts with the political power of the group to produce distinctive patterns of policy design that impact the lives, identity, and perceptions of that group" (Schneider \& Ingram, 2017, p. 320).

Schneider's (2012) discussion of two different policy design traditions, as a noun and as a verb, is instructive. Policy design (as a noun) refers to the policy 
content and to a systematic effort to achieve efficient policy outcomes. This tradition is described as "policycentric" and involves a normative and empirical perspective (Mettler \& Soss, 2004). From a normative perspective, public policies in a democracy are charged with the task of promoting active and engaged citizens, promoting fairness for all, and solving collective problems effectively (Schneider, 2012). From an empirical perspective, policies are seen as a composition of elements that can be described and compared. Fundamental elements include goals or 'problems' to be solved, defining the target population, policy tools, and underlying (normative) assumptions (Schneider \& Ingram, 1997).

Policy designing (as a verb) emphasises the process through which policy content is produced and recognises:

The cognitive biases embedded in the policy as well as attributes that are damaging to the linkage between public policy and democratic principles, such as the intentionally manipulative, deceptive, illogical, meanspirited, and unscientific factors that influenced the choice of design elements. (Schneider, 2012, p. 218)

Central in this tradition is the insight from sociology and social psychology that people have the tendency to organise the social world into 'us' and 'them' or 'the others' who are constructed in terms of dangerous, undeserving, lazy, stupid, or other undesirable traits (Schneider, 2012). Kahneman, Slovic and Tversky (1982) have shown that these biases find their way into public policy designs. In the data sections, I will demonstrate how these biases are manifested in everyday practices at the sport-settlement service which is the focus of this paper. Before doing so, the next section discusses the interplay between top-down policy production and its everyday implementation.

\subsection{Public Institutions and Diversity Workers}

Current social work research demonstrates the wide continuum in which policies are created, implemented and lived. While Woolgar and Neyland (2013) focus on the state and its top-down production of policies (see also McKee, 2009), others study what Lipsky (1980) famously described as "street-level bureaucrats", who give shape to the abstract state policies in their encounters with clients, and Fassin (2015), who concentrates on institutions that are situated between the state and front line policy implementation. Others have described the relationship between agents and clients (Gubrium et al., 2016) or centralised the clienthood process and the role of clients themselves in the formation and implementation of policies (Hall, 2003).

This article focuses on the institutional level. Understanding the state, one should approach it from the margins, where the state is locally produced (Thelen, Vetters, \& von Benda-Beckmann, 2017). Public institutions and their agents are positioned "between the macro-power of the law and policy makers and the micro-powers of the agents in the institutions" (Fassin, 2015, p. 259). Thus, it is the institution's relationship to the state and to the clients through agents that inevitably poses challenges in what "is said and done in the public sphere and the political world" (Fassin, 2015, p. 256). Working in a clearly defined law and policy framework, public institutions have the freedom to produce their own documents and policies to facilitate implementation by streetlevel bureaucrats.

Relevant for this article is what Hagelund (2010) refers to as "diversity dilemmas". Diversity dilemmas describe the dilemmas "diversity workers" (street-level bureaucrats working with migrants and their families) encounter and the strategies they employ when encountering ambivalent situations in which, on the one hand, they are concerned with clients' success in the welfare state institutions (e.g., learning the language and excelling at school) and, on the other hand, want to respect clients' privacy and their right to practice culturally diverse lifestyles (Hagelund, 2010). Diversity dilemmas are inherently linked to the two different agendas in the integration projects discussed by Grillo (2002). One agenda is concerned with incorporating newcomers into society on equal terms, whereas the other agenda is concerned with accommodating diversity within the existing majority framework (Grillo, 2002). These two agendas potentially clash, often leading to conflict between diversity workers (or diversity bureaucrats) and their clients during their encounters.

\section{Methods}

This research was part of a broader program evaluation which included document analysis, observations, a focus group with staff members, and interviews with clients of various programs and partners such as sports organisations, English language schools, and community centres. This article draws on the first three methods with a particular focus on staff meetings and the production of documents. The evaluation project enabled access to and insights into staff work processes and institutional discourses (DeVault, 2006). In other words, the setting (case study) came first and the study topic arose from the nature of this setting (Atkinson \& Hammersley, 2007). Over a period of five months, I spent three to four days per week with staff members in or outside the office and performed light assistance tasks related to program delivery or at community events.

At the time of writing, the programs are run by six core staff members (or "diversity workers", which will be used interchangeably; cf. Hagelund, 2010), of which three are in management and three in delivering. Students in placement and volunteers supported all six staff members. Although the volunteer pool consisted of over twenty volunteers, only four highly involved volunteers (the ones who attended staff meetings and vol- 
unteered multiple times per week and in multiple programs) were included in this research. Student placements generally took place over the course of four to six months. Whereas all staff members were in contact with clients, delivering staff spent most of their time outside the office running the programs, maintaining everyday contacts with clients and representatives of the collaborating schools or community organisations. Time spent inside the office was dedicated to preparing programs, process consent forms or evaluations, and attending staff meetings. The three delivering staff members, or 'street-level bureaucrats' (Lipsky, 1980), are the main contact between clients and schools and the managing staff members. Managing staff maintained and established new contacts with program partners, facilitated work conditions for delivering staff, oversaw long-term program development, and their work included grant proposal writing. Five staff members are first-generation migrants and often drew on their migratory experiences in their contact with clients. Students and volunteers were mostly born in Australia. The staff strongly believed this enabled them to 'stand in their shoes' and provide the support clients need. Some staff has a sport management background, whereas others have a settlement employment background. Students follow a bachelor's in social work, community phycology, or related fields.

Due to the dynamic nature of diversity workers' schedules, observations took place inside and outside the office. In the office, I focussed on staff meetings, informal conversations among staff, and staff preparing or processing program delivery. Observations outside the office mainly involved the interaction between staff members and clients and partner representatives, the delivery of the program, and community events. After a day in the office, a meeting, or an outdoor activity, detailed field-notes were kept in a journal. Notes on conversations between staff members and/or clients and staff meeting summaries were included in the journal. When I followed staff members in program delivery, I would perform basic assistance tasks and always (both in and outside the office) assumed the role of researcher and was introduced as such to partners and clients.

Additionally, I conducted a two-hour focus group with four staff members and two volunteers. The leading questions in the focus group included how staff members describe their clients, how they perceive participants' needs, what kind of contributions staff could personally offer to clients' settlement, and the kind of (diversity) challenges they encounter. Also, how funding requirements relate to the need of clients and strategies staff members employ to meet the requirements and also respond to participants needs was included in the focus group. The focus group was held three months into data collection and discussion topics were informed by previous observations, topics discussed in staff meetings, and informal conversations with clients, staff, and program partners. The focus group provided the opportunity to ask for clarification on particular topics (such as the use of consent and evaluation forms and the workload of program deliverers), but also enabled staff to reflect on their work practices and to discuss challenges in a way the routinised staff meetings cannot.

Several ethical considerations influenced the research. The culturally diverse environment in which the research was undertaken required a particular ethical awareness and sensitivity. As a Dutch migrant, white, and an educated woman of feminist upbringing (including the belief in gender equity, independence, and the importance of voicing one's own opinion), I tried to find a balance between respecting clients' own values and encouraging clients to be honest in interviews when asking about their program experiences (as a researcher) and to make their own decisions (as a delivery assistant). In finding this balance I followed ethical standards set by diversity workers such as foregrounding clients' decision-power and asking for support of a language school teacher or a client's friend for, e.g., interpretation help in the case of language difficulty. Teachers or friends were experienced in communicating with a particular client and were helpful in establishing confidence.

My role as researcher and assistant in program delivery resulted at times in ambivalent moments that required additional ethical considerations beside the standard ethical practices. In the weekly staff meetings, I was often given time to explain how I experienced the program delivery, what I thought could be improved, and what my 'success moment' of the week was from a staff member, rather than a researcher, perspective. The 'hat' I was wearing could change a few times within one setting, for example, a staff meeting. This flexibility enabled me to connect in different ways with staff members, clients, and others in the field. It also required constant reflexivity, whether I was in a critical researcher role or in a supportive assistance role. Ethics approval was obtained by the Victoria University Human Research Ethics Committee and pseudonyms were allocated to protect respondents' privacy.

The focus group was electronically recorded and, together with the journal and internal documents, transcribed using the NVivo software program. All data, including those collected for this article and the evaluation project, were initially analysed using a thematic analysis approach. A second thematic analysis for this article focussed on the above-described methods. The second analysis was informed by Schneider and Ingram's theorisation of policy design that places an emphasis on how clients, problems and solutions are socially constructed in combination with the fact that technologies of control are increasingly textual and discursive (Smith, 2005). The latter analysis resulted in codes (e.g., Australian cultural ideal, migrant history, staff motivation) that were consequently organised in subthemes (e.g., staff coping strategies, settlement needs, and organisation hierarchies) and finally in the two themes discussed in the next section. 


\section{6. "How Do We Put Him in the System?": A Sport-Based Settlement Service in Melbourne West}

The question posed in a staff meeting, "how do we put him in the system?", reflects the broader concern of diversity workers and how they can cater to their clients best, and it illustrates the creativity of diversity workers when dealing with everyday challenges. The ethnographic data is presented in two sections based on the main themes. Whereas the first theme describes staff concerns and strategies related to reaching the right clients and providing the right settlement services within the organisation structure, the second theme presents data on how this empowerment is restricted. Overall, the two sections describe the constant struggle diversity workers find themselves in: breaking free from a staff-client power relation and empowering clients while being pulled back into a stigmatising approach to client construction.

\subsection{Eligible Clients and Program Design}

Eligible clients of the sport-settlement service include migrants who have arrived in Australia as humanitarian entrants or through the family member visa program in the last five years. The service collaborates with language schools to access most of their clients. The language schools run the Adult Migrant English Program which is overseen by the Australian Government, Department of Education and Training. The 510 English language tuition hours provided through the program support migrants from a non-English background after their arrival in Australia to start learning English or build on existing language skills. However, settlement needs vary largely across clients and, notably, continue to exist after completing the 510 hours or after having spent five years in Australia. The definition of eligible clients that fall under the Department of Social Services funding, in combination with how the service accesses its clients, places restrictions on migrants who are eligible for the sport-settlement service. The narrow categorisation of eligible clients is described as highly problematic by most staff members. Hamia (staff member, female, 30s) describes how, as a consequence, the program design does not necessarily address clients' needs or reach the right clients:

The government's focus for the next three years is employment, which is not a client's priority in the first few months after arrival. And it really shouldn't be because they've got heaps to deal with, there's the trauma, language. If we prioritise employment more, it will change the way the program looks like.

In a similar vein, Linda (staff member, female, 20s) discussed with her colleagues in a staff meeting a client who has participated in their programs for two years and wants to continue to do so but is not eligible anymore as he has spent more than five years in Australia. It is, however, beneficial for the service to continue to support him considering his leadership role in the local SouthSudanese community and can motivate his peers to participate in the settlement programs. The staff agreed that he should be part of one of the programs, upon which Linda asked: "How do we put him in the system?" In a practical sense, the system refers to a computer program in which clients' data is administrated. Consent forms filled out by clients form the basis for this digital collection and are discussed in depth in the following section. On a more abstract level, the system refers to a process that dictates who is included and who is excluded. In other words, does a client 'tick' the eligibility boxes? The staff was confronted with a dilemma: how can this man participate in a program without having to be registered? To continue supporting and to maintain the relationship with this particular client, but not having to register the client in the computer system, the staff members concluded that the volunteer program was the best option. The volunteer program was established a few years ago and is open for anyone, (former) clients and non-clients alike, to join and in this program volunteers assist core staff members in delivering or preparing programs. This example demonstrates a strategy which staff members have developed to cope with a bureaucratic challenge that is a result of being situated between government guidelines and clients' (and the settlement service's) needs (cf. Fassin, 2015). This example not only demonstrates how coping strategies include clients, but can also simultaneously have exclusive characteristics. Since the client offered the organisation additional value (direct contact with the South-Sudanese community), he was encouraged to participate in the volunteer program in a way other clients in a similar situation, but without additional value, might not have.

The deviation between needs and requirements is recognised by many other settlement services. To be able to cater to non-eligible clients, these services seek funding elsewhere and design additional programs. Naturally, this coping strategy increases the workload of staff in an already competitive neoliberal 'more-for-less' settlement service sector. As a response to the imbalance, Amar (staff member, male, 30s) emphasised the importance of community-needs:

We are looking at a problem in society and trying to provide for that, solve that issue. Our service probably needs to be more responsive to what is needed within the community and try to address that, as opposed to continuing to deliver program after program.

Although it remains unclear throughout the interview what exactly Amar means by "problems in society", they will not be solved when depending solely on funding bodies' requirements. Amar is the highest placed manager and his rather abstract formulation of the organisation's aim, "looking for a problem in society" and "being re- 
sponsive to what is needed" is in sharp contrast with the more hands-on approach by the other two managers and delivering staff. During my ethnographic research, developments such as described by Amar were communicated to the delivering staff by the other two managing staff members, direct communication was scarce. In staff meetings, attending staff (and at times students in placement) discussed strategies regarding how they could be more responsive to individual and community settlement needs. In an effort to engage more with clients and include them in the program design, staff organised formal community meetings and one-on-one informal conversations. Despite the staff's genuine intention to include and empower clients, it proved to be a difficult task to get out of the staff-client relation.

The objective of the service is to contribute to migrants' Australian linguistic and cultural literacy but simultaneously recognise and respect cultural and religious background. Diversity workers consciously made an effort to learn about clients' cultural traditions and in conversations wanted to learn about words/phrases in clients' native languages. Staff would be made sure to provide Halal meat at barbeques and were aware of Islamic and other feast days to plan programs accordingly. However, staff also encountered "diversity dilemmas" (Hagelund, 2010) which are clearly illustrated by the discussion of whether sports activities should be sexseparated or mixed. Female clients often expressed a preference for separated sports teams as these clients had less experience with sports and played less 'harshly' than male clients. On the other hand, gender-mixed teams, and when taken further: gender-neutral treatment and women empowerment are central Australian ideals newcomers are expected to align with. Solutions to this cannot be found in policy documents but were discussed in staff meetings and often staff prioritised clients' preferences (and to ensure female participation) and gender norms could be discussed at another time and another place-a similar conclusion can be found in Hagelund (2010) when the author discusses mixed youth swimming classes.

\subsection{Starting Over, Becoming the Same?}

Consent and evaluation forms are central bureaucratic practices through which staff generates paperwork. The two forms are policy requirements and provide remarkable insight into how top-down policies and bottom-up implementation interact. Prior to any program, sport or non-sport, clients are asked by delivering staff to fill out a consent form upon which they agree to take responsibility for any incidents. The consent form also includes social demographic questions (e.g., age and sex) as well as the following: "which language do you speak at home?", "how much time have you spent in Australia?", "on which visa did you enter Australia?" The answers are used anonymously, for internal use as well as to report to funding bodies. Evaluation forms are used similarly to report and update funding bodies and other program partners about the successes and impact of the settlement programs.

The forms were a source for staff discussions and concern. Clients with low English skills were generally unable to interpret and respond to questions, responses were not always clear, and the results of the consent and evaluation forms were shallow and questionable (e.g., are clients in the position to be critical and honest?). To illustrate this, I will describe two observations. One day, when I was assisting Bilal (staff member, male, 20s) with distributing and collecting evaluation forms, I experienced the following:

Bilal and I distributed the forms to the seven students in the classroom. The teacher had just left to get coffee. Some students translated questions with their phones, another student asked me to assist her. I formulated the questions in different ways with help from another student but remained unsuccessful with some questions. She gave the pencil to me and looked at the form, asking me to complete it. When I returned the pencil, she refused, and I realised she couldn't (or was not confident to) write in English. We left some of the questions unanswered. She seemed disappointed with the situation, not being able to answer the questions. (entry from a personal journal, 25 August 2018)

My experience represents what diversity workers face on a daily basis: how to return to the office with the data and simultaneously maintaining a confidential relationship that is based on trust and understanding instead of disappointment and disempowered clients. A second example is concerned with consent forms at an employment course. Fiona asked clients to fill out a consent form; most were able to answer the questions. One client received help from the teacher. When clients came across the question "on what visa did you enter Australia?" they started whispering, unsure how to respond. Fiona intervened and explained it asked for the Humanitarian visa subclass they had been granted. The situation caused confusion because some could not remember the exact subclass or seemed hesitant to write it down. Fiona explained to the women sitting next to me that it was probably 202 or 204 (respectively, subclass Global Special Humanitarian and Women at Risk under the Humanitarian Program).

The language and ethical challenges were recognised by managing staff, but the deliverers and students in placement took initiative to change the forms to make their work less awkward and establish or maintain a confidential relationship, which is vital in social work. Teachers played a central role in another strategy diversity workers drew on. As the forms were completed in the classroom, language teachers were often asked to help to interpret the questions. Some proactive teachers saw these moments as an opportunity to teach their students about reading and filling out bureaucratic forms. Other 
times it was up to the staff member to make the best of the situation.

Migration-related questions might seem like unequivocal questions that for most participants are, or have become, just as straightforward as their name and email address. However, apart from the practical challenges the forms provide, they also place emphasis on where clients originally come from, that they are not originally from Australia, and potentially enforce the us/them relationship (cf. Schneider, 2012): 'us', staff members who are well acquainted with the English language and Australian culture, teaching 'them', clients, what is expected from new citizens. Although staff members acknowledge they can learn from clients in terms of cultural traditions, clients are mostly described in terms of students and the ones in a learning process. A quote from Fiona highlights this:

Some [clients] say: 'I'm a doctor, I'm a technician'. I had completely forgotten that these people actually have lives, how condescending of me to not think that was the case. These people had skills, they just [had acquired these] in another country. So that was my lesson of the day and I now ask it all the time.

Fiona's reflection on her thinking narrates how migrants' backgrounds are perceived. Although Fiona explains she has become aware of it and now asks new clients about their education and employment background "all the time", this is generally not the case in broader Australian society. Workplace discrimination and migrants' pre-migration education and employment experiences continue to be under-valued or not recognised at all (Moran, 2011). Although not confirmed by staff members, condescending behaviour (the attitude of patronising superiority), and seeing clients as objects of learning or 'blank canvases' may be reinforced by clients being continuously referred to as "students" of the English language schools.

Hage (2000, pp. 50-51) critically reflects on citizenship papers in the Australian context and writes:

The very possession of these citizenship papers is stigmatising at a practical, non-official level since their possession and production is only required from those who have not acquired their citizenship by birth. Thus, what is the proof of belonging to the state (citizenship) can, in a practical sense, operate as a proof of national non-belonging to the dominant culture.

Citizenship papers acknowledge newly arrived migrants as legal residents of the national territory. However, and similar to the consent forms, the papers do not guarantee non-official acceptance and rather operates as proof of non-belonging, Hage (2000) argues. Categories such as "culturally and linguistically diverse migrants" and "refugees" operate in a similar stigmatising vein. Clients of the settlement service have all continued their lives in a new country and started over after having to (forcefully) leave their countries of birth. The data goes to question whether clients are really starting over or are 'stuck' in a refugee/student/culturally and linguistically diverse-migrant category that is emphasised in forms and documents.

\section{Conclusions and Discussion}

Building on Schneider and Ingram's (1993) approach to researching policy design and the construction of societal problems, solutions, and target populations, this article has sought to better understand these practices on the public institutional level. A growing body of literature has provided critical voices and has contributed to the development of the sport-for-development field. Nonetheless, substantial research focussing on policy design and implementation is still lacking.

This article draws on five-month qualitative research prioritising staff's everyday work processes with a focus on staff meetings and the production of documents (cf. DeVault, 2006). At times staff meetings and documents supplemented each other while at other times the two work processes were in conflict. Strategies not offered in official policy documents were discussed in staff meetings to share best practices and ensure consistency among staff members (e.g., organising sex-separated sports settings). In this sense, meetings and documents complement each other. On the other hand, meetings were also used to discuss strategies to avoid the use of documents and 'the official system' to be able to cater as many clients as possible (e.g., including a non-eligible client in the volunteer program to avoid having to register him in the system). Other coping strategies were discussed in this article, including the adjustment of forms and seeking alternative financial sources to offer clients the most suitable and ethically sensitive support. These findings are consistent with Devlieghere (2017), who examines the interaction between Electronic Information Systems and social workers in the context of child welfare services and describes how social workers shape and bend regulations. In doing so, although thereby also risking the exclusion of broader social-political principles, social workers were able to be more responsive to the needs and concerns of clients and their families (Devlieghere, 2017).

In this article, I have shown how staff members' client constructions in meetings and documents reinforce othering, migrant categorisation and support a deficit, reductionist model. While clients were talked about in respectful and empowering terms in meetings or informal discussions among staff, policy documents (program designs and grant applications) and consent/evaluation forms reinforce migrant categorisation. Although the "culturally and linguistically diverse" category, prominent in all documents of the sport-based settlement service, replaced "non-English speaking" for its more inclusive assets, it too encompasses conflicting def- 
initions and is heavily criticised for its othering character (Sawrikar \& Katz, 2009). The fixation on collecting clients' socio-demographic data emphasises their nonAustralianness and questions whether they will ever become a 'real' citizen. On a national level, it contributes to upholding Australia's essentialist national approach to citizenship.

Settlement services in Australia are situated in a migratory regime in which migrant integration is framed as a policy issue concerned with the assimilation of newcomers and the maintenance of Anglo-culture hegemony. Portes (2010, p. 1550) writes that:

The problem, however, is not that they [newcomers] threaten the basic social and cultural order of these societies, but that they remain outside of it. Such groups do not 'remake' the mainstream, they just fail to join it for various reasons.

In line with Portes (2010), and based on the data, I argue that a deficit reductionist representation of migrants may limit the discursive opportunities for identification and participation of migrants in wider society, and thus may have the opposite effect from what governments and the sport-for-development sector aim to accomplish (cf. Roggeband \& Verloo, 2007). This is consistent with Robertson's (2018) findings, which have introduced the term "status-making" in order to understand and challenge taken-for-granted migrant types and categories, as these can have a profound impact on a migrant's life.

\section{Acknowledgments}

I wish to thank the anonymous reviewers for their critical yet constructive feedback on earlier drafts of the manuscript. I would also like to thank the staff members who generously shared their time and stories with me and who welcomed me into their organisation.

\section{Conflict of Interest}

The author declares no conflict of interests.

\section{References}

Anthias, F. (2012). Transnational mobolities: Migration research and intersectionality. Nordic Journal of Migration Research, 2(2), 102-110.

Atkinson, P., \& Hammersley, M. (2007). Ethnography: Principles in practice (3rd ed.). London: Routledge.

Boese, M., van Kooy, J., \& Bowman, D. (2018). Humanitarian migrants, work and economic security on the urban fringe: How policies and perceptions shape opportunities. Melbourne: Brotherhood of St Laurence.

Bouma, G. (2006). Australian soul: Religion and spirituality in the twenty-first century. Cambridge: Cambridge University Press.

Coakley, J. J. (2011). Ideology doesn't just happen: Sports and neoliberalism. Revista da Alesde, 1(1), 67-84.

Coalter, F. (2007). Sport a wider social role: Whose keeping the score? London: Routledge.

Coalter, F. (2010). The politics of sport-for-development: Limited focus programmes and broad gauge problems? International Review for the Sociology of Sport, 45(3), 295-314.

Commonwealth of Australia. (2014). Australian citizenship: Our common bond. Canberra: Communication and Engagement Branch of the Department of Home Affairs.

DeVault, M. L. (2006). Introduction: What is institutional ethnography? Social Problems, 53(3), 294-298.

Devlieghere, J. (2017). The logic of the database: In search of responsive social work (Unpublished Doctoral dissertation). Ghent University, Ghent, Belgium.

Ekholm, D., \& Dahlstedt, M. (2017). Football for inclusion: Examining the pedagogic rationalities and the technologies of solidarity of a sports-based intervention in Sweden. Social Inclusion, 5(2), 232-240.

Fassin, D. (2015). At the heart of the state: The moral world of institutions. Pluto Press.

Grillo, R. D. (2002). Immigration and the politics of recognizing difference in Italy. In R. D. Grillo \& J. Pratt (Eds.), The politics of recognising difference: Multiculturalism Italian-style (pp. 1-24). Aldershot: Ashgate.

Gubrium, J., Andreassen, T., \& Solvang, P. (2016). Reimagining the human service relationship. New York, NY: Columbia University Press.

Hage, G. (2000). White nation: Fantasies of white supremacy in a multicultural society. New York: Routledge.

Hagelund, A. (2010). Dealing with the dilemmas: Integration at the street-level in Norway. International Migration, 48(2), 79-102.

Hall, C. (2003). Constructing clienthood in social work and human services. London: Jessica Kingsley Publishers.

Harris, A. (2009). Shifting the boundaries of cultural spaces: Young people and everyday multiculturalism. Social Identities, 15(2), 187-205.

Houlihan, B., Bloyce, D., \& Smith, A. (2009). Developing the research agenda in sport policy. International Journal of Sport Policy and Politics, 1(1), 1-12.

Jeanes, R., O'Connor, J., \& Alfrey, L. (2015). Sport and the resettlement of young people from refugee backgrounds in Australia. Journal of Sport and Social Issues, 39(6), 480-500.

Kahneman, D., Slovic, P., \& Tversky, A. (1982). Judgment under uncertainty: Herusitics and biases. Cambridge: Cambridge University Press.

Klocker, N., \& Dunn, K. M. (2003). Who's driving the asylum debate? Newspaper and government representatoins of asylum seekers. Media International Australia Incororpating Culture and Policy, 109(1), 71-92.

Kofman, E. (2005). Citizenship, migration and the reassertion of national identity. Citizenship Studies, 9(5), 453-467. 
Lipsky, M. (1980). Street-level bureaucracy: Dilemmas of the individual in public services. New York, NY: Russel Sage Foundation.

Markus, A. (2014). Attitudes to immigration and cultural diversity in Australia. Journal of Sociology, 50(1), 10-22.

McDonald, B. (2016). Coaching whiteness: Stories of 'Pacifica exotica' in Australian high school rugby. Sport, Education and Society, 21(3), 465-482.

McDonald, B., Rodriguez, L., \& George, J. R. (2018). 'If it weren't for rugby l'd be in prison now': Pacific Islanders, rugby and the production of natural spaces. Journal of Ethnic and Migration Studies. https://doi.org/10.1080/1369183X.2018.1492909

McDonald, B., Spaaij, R., \& Dukic, D. (2018). Moments of social inclusion: Asylum seekers, football and solidarity. Sport in Society.

McKee, K. (2009). Post-Foucauldian governmentality: What does it offer critical social policy analysis? Critical Social Policy, 29(3), 465-486.

Mettler, S., \& Soss, J. (2004). The concequences of public policy for democratic citizenship: Bridging policy studies and mass politics. Perspectives and Politics, 2(2), 55-73.

Moran, A. (2011). Multiculturalism as nation-building in Australia: Inclusive national identity and the embrace of diversity. Ethnic and Racial Studies, 34(12), 2153-2172.

Olliff, L. (2008). Playing for the future: The role of sport and recreation in supporting refugee young people to 'settle well' in Australia. Youth Studies Australia, 27(1), 52-60.

Portes, A. (2010). Migration and social change: Some conceptual reflections. Journal of Ethnic and Migration Studies, 36(10), 1537-1563.

Refugee Council Australia. (2010). A bridge to a new culture: Promoting the participation of refugees in sporting activities. Sydney: RCOA.

Robertson, S. (2018). Status-making: Rethinking migrant categories. Journal of Sociology. https://doi.org/10.1177/1440783318791761

Roggeband, C., \& Verloo, M. (2007). Dutch women are liberated, migrant women are a problem: The evolution of policy frames on gender and migration in the Netherlands. Social Policy and Administration, 41(3), 271-288.

Rowe, D. (2017). We're all transnational now: Sport in dynamic sociocultural environments. Sport in Society: Cultures, Commerce, Media, Politics, 20(10),
1470-1484.

Sawrikar, P., \& Katz, I. (2009). How useful is the term 'culturally and linguistically diverse' (CALD) in Australian research, practice, and policy discourse? Kensington: Social Policy Research Centre, University of New South Wales. Retrieved from unsworks.unsw.edu.au/ fapi/datastream/unsworks:39250/bin47a64732-6a49 -49aa-aad2-39aa4f68bf76?view=true

Schneider, A. (2012). Policy design and transfer. In E. J. Araral, S. Fritzen, M. Howlett, M. Ramesh, \& X. Wu (Eds.), Routledge handbook of public policy (pp. 217-228). London: Routledge.

Schneider, A., \& Ingram, H. (1993). Social construction of target populations: Implications for folitics and policy. American Political Science Review, 87(2), 334-347.

Schneider, A., \& Ingram, H. (1997). Policy design for democracy. Lawrence, KS: University of Kansas Press.

Schneider, A., \& Ingram, H. (2017). Framing the target in policy formulation: The importace of social constructions. In M. Howlett \& I. Mukherjee (Eds.), Handbook for policy formation. Cheltenham and Northampton: Edward Elgar Publishing.

Smith, D. (2005). Institutional ethnography: A sociology for people. Lanham, MD: AltraMira.

Spaaij, R. (2013). Sport, social cohesion and community building: Managing the nexus. In P. Leisink, P. Boselie, M. van Bottenburg, \& D. M. Hosking (Eds.), Managing social issues: $A$ public values perspective (pp. 107-125). Cheltenham: Edward Elgar.

Spaaij, R., \& Broerse, J. (2018). Diaspora as aesthetic formation: Community sports events and the making of a Somali diaspora. Journal of Ethnic and Migration Studies. https://doi.org/10.1080/1369183X.2018.1427052

Stone, D. (2011). Policy paradox: The art of political decision making (3rd ed.). New York, NY: W.W. Norton \& Company.

Thelen, T., Vetters, L., \& von Benda-Beckmann, K. (2017). Stategraphy: Toward a relational anthropology of the state. New York, NY: Berghahn Books.

Walsh, J. P. (2014). The marketization of multiculturalism: Neoliberal restructuring and cultural difference in Australia. Ethnic and Racial Studies, 37(2), 280-301.

Woolgar, S., \& Neyland, D. (2013). Mundane governance: Ontology and accountability. Oxford: Oxford University Press.

Young, I. M. (2000). Inclusion and democracy. Oxford: Oxford University Press.

\section{About the Author}

Jora Broerse is a PhD candidate in Sociology at Victoria University, Melbourne, Australia. In 2017, she completed the Research Master Social Sciences at the University of Amsterdam, the Netherlands. Her research is concerned with lived multiculturalism, migrant integration, and space making practices in the context of sport in super-diverse neighbourhoods. Jora Broerse's work has previously been published in the Journal for Ethnic and Migration Studies and the Journal for Intercultural Studies. 